\title{
Electromagnetic interference of GSM mobile phones with the implantable deep brain stimulator, ITREL-III Wolfgang Kainz ${ }^{* 1}$, François Alesch ${ }^{2}$ and Dulciana Dias Chan ${ }^{3}$
}

Address: ${ }^{1}$ Department of Mobile Communications Safety, ARC Seibersdorf Research, Austria, ${ }^{2}$ Department of Neurosurgery, AKH Vienna, Austria and ${ }^{3}$ Department of Biomedical Engineering, Johns Hopkins University, MD, USA

Email: Wolfgang Kainz* - kainz@ieee.org; François Alesch - francois.alesch@univie.ac.at; Dulciana Dias Chan - dulciana@jhu.edu

* Corresponding author

Published: 7 May 2003

BioMedical Engineering OnLine 2003, 2:I
Received: 23 December 2002

Accepted: 7 May 2003

This article is available from: http://www.biomedical-engineering-online.com/content/2/I/II

(C) 2003 Kainz et al; licensee BioMed Central Ltd. This is an Open Access article: verbatim copying and redistribution of this article are permitted in all media for any purpose, provided this notice is preserved along with the article's original URL.

\begin{abstract}
Background: The purpose was to investigate mobile phone interference with implantable deep brain stimulators by means of 10 different $900 \mathrm{Mega} H \mathrm{Hertz}(\mathrm{MHz})$ and 10 different $1800 \mathrm{MHz}$ GSM (Global System for Mobile Communications) mobile phones.

Methods: All tests were performed in vitro using a phantom especially developed for testing with deep brain stimulators. The phantom was filled with liquid phantom materials simulating brain and muscle tissue. All examinations were carried out inside an anechoic chamber on two implants of the same type of deep brain stimulator: ITREL-III from Medtronic Inc., USA.
\end{abstract}

Results: Despite a maximum transmitted peak power of mobile phones of I Watt (W) at I800 $\mathrm{MHz}$ and $2 \mathrm{~W}$ at $900 \mathrm{MHz}$ respectively, no influence on the ITREL-III was found. Neither the shape of the pulse form changed nor did single pulses fail. Tests with increased transmitted power using $\mathrm{CW}$ signals and broadband dipoles have shown that inhibition of the ITREL-III occurs at frequency dependent power levels which are below the emissions of GSM mobile phones. The ITREL-III is essentially more sensitive at $1800 \mathrm{MHz}$ than at $900 \mathrm{MHz}$. Particularly the frequency range around $1500 \mathrm{MHz}$ shows a very low interference threshold.

Conclusion: These investigations do not indicate a direct risk for ITREL-III patients using the tested GSM phones. Based on the interference levels found with CW signals, which are below the mobile phone emissions, we recommend similar precautions as for patients with cardiac pacemakers: I. The phone should be used at the ear at the opposite side of the implant and 2 . The patient should avoid carrying the phone close to the implant.

\section{Background}

Today, the use of mobile phones is widespread and the number of users is increasing rapidly. It is generally known that an electromagnetic field of adequate intensity and frequency may interfere with implanted devices. Mobile phones are regarded as a potential source of electromagnetic interference with pacemakers [1]-[18] and defibrillators $[6,19,20]$. An extensive review of the litera- ture $[21,22]$ demonstrated that up to now no examinations on electromagnetic compatibility aspects of deep brain stimulators (DBS) and mobile phones have been published. The malfunctions (inhibition, switch to the safety modus, i.e. stimulation with a fixed rate, and stimulation with a false signal) reported with pacemakers [1][18] due to the use of mobile phones may lead to discomfort and in rare cases to menacing situations for the 
pacemaker patient. These malfunctions depend on various parameters: frequency, transmitting power, modulation principle of the mobile phone system, distance between mobile phone and pacemaker, implantation depth, operating mode of the pacemaker as well as the interference immunity of the pacemaker. For older pacemakers a safety distance of 6 inches ( 15 centimeters) is sufficient to avoid malfunctions, although some publications recommend less than 6 inches. The use of the mobile phone on the opposite side of the pacemaker's location reduces the probability of interference. Subsequently, pacemaker patients should not carry the mobile phone in the breast pocket close to the pacemaker or, if the pacemaker is located in the abdomen, not on a belt, when it is switched on. Defibrillators seem to be less sensitive than pacemakers regarding electromagnetic fields emitted by mobile phones. Generally, the same precautions ( 6 inches or 15 centimeter minimum distance) as in the case of pacemakers should be encouraged. If these precautions are adhered to the possibility of interference with defibrillators can be minimized.

The increasing use of neurostimulators and mobile phones, and the lack of information on possible disturbance of DBSs due to exposure from mobile phones motivated us to carry out this study. We studied the interference of the DBS ITREL-III from Medtronic Inc. (Minneapolis, MN, USA) with GSM mobile phones operating at $900 \mathrm{MHz}$ and $1800 \mathrm{MHz}$ and with broadband diploes in the frequency range from $500 \mathrm{MHZ}$ up to 2400 $\mathrm{MHz}$. Unlike pacemakers and defibrillators, DBSs have no sensing inputs and therefore they should be more robust regarding electromagnetic interference. However, stimulation leads could act as antenna, picking up radio frequency (RF) currents and leading them into the device. Feed through filters should be able to handle this problem. However, the manufacturer did not disclose information of the implant design, the electronic circuit design, whether feed though filters where used or not and which other electromagnetic compatibility precautions were taken.

Neurological pulse generators are used as DBSs in the treatment of Parkinson's disease or as spinal cord stimulators. This study deals only with the ITREL-III as a DBS. Located in the chest region under the skin, the DBS stimulates certain areas of the brain, namely the thalamus or subthalamus $[23,24]$. Due to its superior programming possibilities, the ITREL-III and ITREL-II are the DBSs preferred by our center for neurosurgery. A programming device can telemetrically adjust the stimulation parameters such as frequency, amplitude, and pulse duration. Two critical locations of the phone in respect of interference that correspond to typical use scenarios can be found: The region around the ear due to the closeness of the mobile phone antenna to the leads of the DBS and the breast re- gion due to the potential closeness of the mobile phone to the DBS.

\section{Methods}

All tests were performed in vitro using a phantom especially developed for experiments with the ITREL-III from Medtronic Inc. (Minneapolis, MN, USA). The experiments were carried out on two implants of the same type, with standard electrodes (Medtronic Type \# 3387) and leads with a length of 51 centimeter $(\mathrm{cm})$. One implant had already been used in a patient and therefore it showed a low battery capacity. Unipolar stimulation was used between the positively charged implant case and the negatively charged electrode tip (pole 0). This stimulation was chosen because interference tests with pacemakers and defibrillators have uncovered unipolar stimulation to be more sensitive than bipolar stimulation $[10,12,20]$. Electromagnetic interference occurs often when electronic devices are brought to their functional limits. Knowing that some stimulation settings are not usual stimulation parameters, we selected these stimulation settings to operate the implant at its functional limits provoking possible interference. In addition to these extreme parameters, tests with typically used stimulation parameters (stimulation amplitude 1 Volt (V) and $3 \mathrm{~V}$, pulse duration 90 microseconds ( $\mu \mathrm{s}$ ) and $150 \mu$ s and frequency $90 \mathrm{~Hz}$ and 120 $\mathrm{Hz}$ ) were performed. Table 1 shows all stimulation parameter settings.

The phantom consists of three parts: the skull, the trunk, and the skull-trunk connection as shown in Figure 1. The skull and trunk are filled with liquid phantom materials simulating brain tissue and muscle tissue. The skull-trunk connection establishes the electrical connection between the two liquid phantom materials and avoids mixing them. The skull-trunk connection consists of a tube with an inside diameter of $4.4 \mathrm{~cm}$ and is filled with a jelly phantom material simulating muscle tissue. We positioned the ITREL-III as it is typically placed in DBS patients. The implant and the leads are placed $1 \mathrm{~cm}$ below the inner surface of the phantom shell. This results in a 1 $\mathrm{cm}$ thick layer of phantom liquid between the inner surface of the $3 \mathrm{~mm}$ thick phantom shell and the surface of the implant. Figure 2 shows the implant holder and the lead holder. The electrode goes $3.5 \mathrm{~cm}$ above the hair line, $7 \mathrm{~cm}$ deep into the skull. Figure 3 shows the electrode and the electrode holder in the phantom skull. Reflections and the influence of external interference sources were minimized using a shielded anechoic chamber for all experiments (see Figure 4).

Common phantom liquids can only be produced for a single frequency or a limited frequency range. Because permittivity and conductivity are functions of frequency, it was necessary to develop two phantom materials. The 
Table I: DBS Parameter Settings

\begin{tabular}{|c|c|c|c|}
\hline Setting & Amplitude & Pulse duration & Frequency \\
\hline & {$[\mathrm{V}]$} & {$[\mu \mathrm{s}]$} & {$[\mathrm{Hz}]$} \\
\hline I & 10.5 & 60 & 28 \\
\hline 2 & 0.3 & 60 & 28 \\
\hline 3 & 0.3 & 450 & 28 \\
\hline 4 & 0.3 & 450 & 130 \\
\hline 5 & I & 90 & 90 \\
\hline 6 & I & 90 & 120 \\
\hline 7 & 3 & 150 & 90 \\
\hline 8 & 3 & 150 & 120 \\
\hline
\end{tabular}

DBS settings used for interference experiments with GSM mobile phones and broadband dipoles

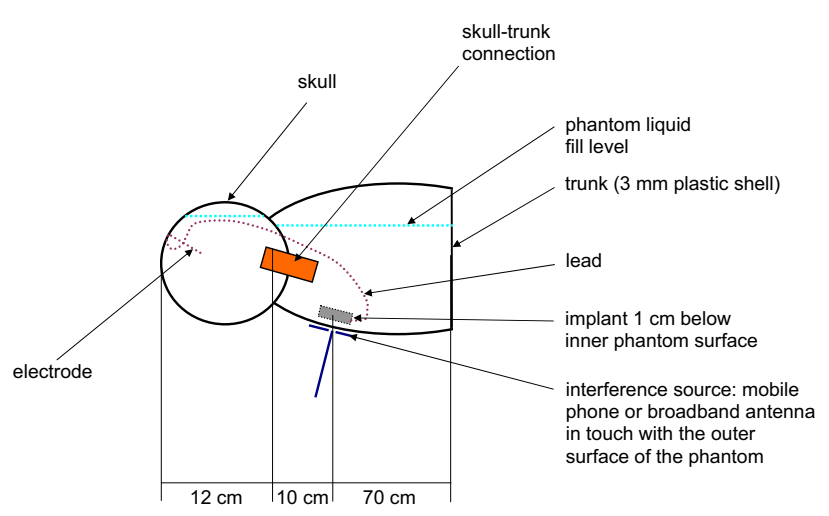

Figure I

Phantom Diagram. Arrangement of the entire phantom with implant, lead, and electrode.

liquid phantom materials used in this experiment were mixed for $900 \mathrm{MHz}$ and $1800 \mathrm{MHz}$. For the frequency range from $500 \mathrm{MHz}$ up to $1300 \mathrm{MHz}$ the phantom liquids mixed for $900 \mathrm{MHz}$ were used. For the upper frequency range ( $1300 \mathrm{MHz}-2400 \mathrm{MHz})$, liquids for 1800 $\mathrm{MHz}$ were used. The composition of the phantom materials is listed in Table 2. The dielectric properties of human tissue were taken from [25]. This data is available on the FCC web site http://www.fcc.gov/fcc-bin/dielec.sh which were derived from the 4-Cole-Cole analysis by S. Gabriel. The respective properties of the phantom liquids and the jelly phantom material were measured with the "Dielectric Probe Measurement System" HP-85070M from Hewlett Packard. All dielectric properties can be found in Table 3.

In order to determine the influence of the plastic phantom shell on the field distribution, the difference in the atten-

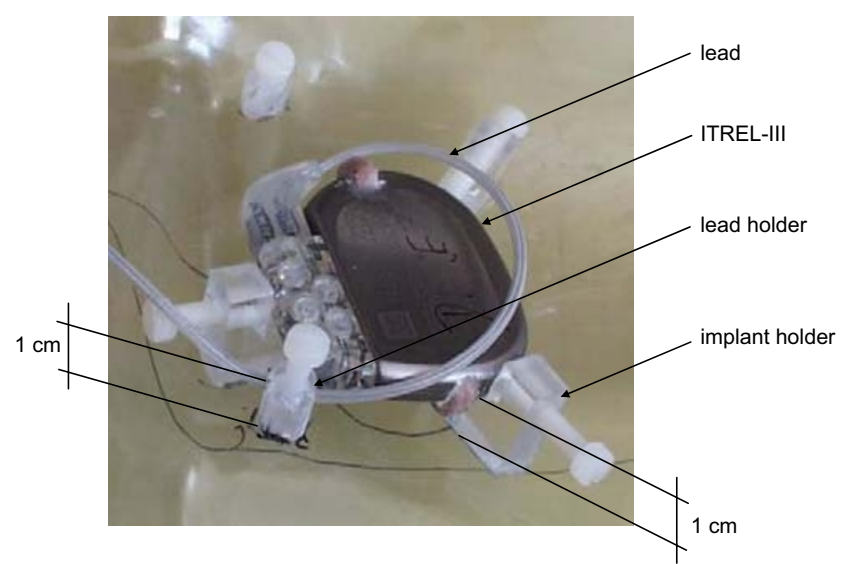

Figure 2

Implant and Lead Holders. ITREL-III in the implant holder and the lead in the lead holder inside the phantom.

uation between two dipoles with and without phantom shell were measured. The network analyzer HP 8753D was used for measuring the attenuation. To ensure that the maximum attenuation was found, the dipoles were arranged in a way that the electromagnetic wave had to penetrate three synthetic material layers. The maximum attenuation was $1 \%$. During the interference immunity tests only one material layer was situated between the emitting antenna and the phantom liquid. Therefore, an essential influence of the phantom shell can be excluded.

The interference tests were performed in two steps. First we exposed the ITREL-III to electromagnetic fields of mobile phones. In addition we wanted to find out at which transmitted power an influence on the ITREL-III might oc- 


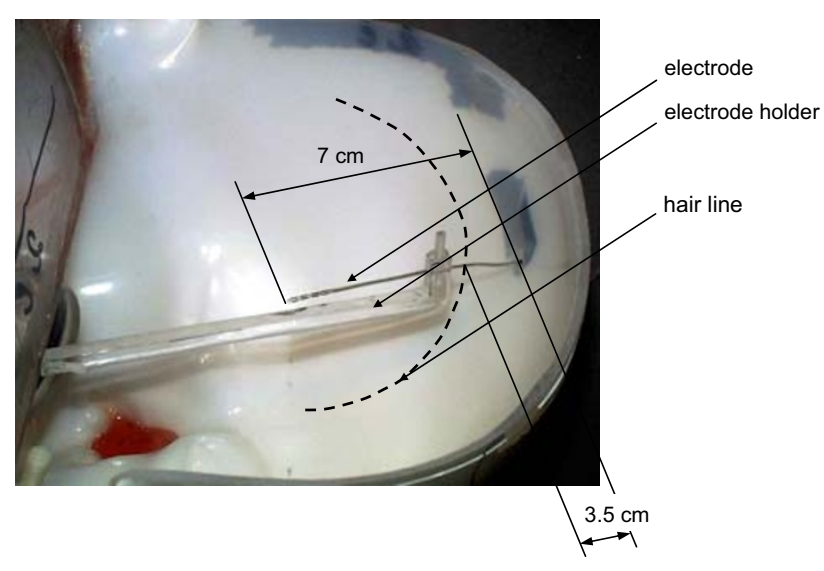

Figure 3

Electrode and Electrode Holder. Electrode and electrode holder in the phantom skull.

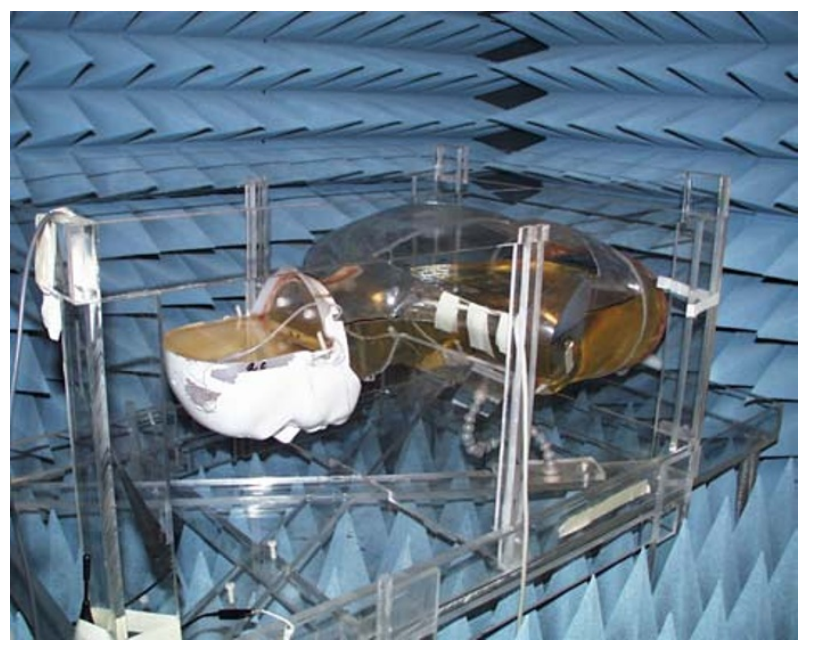

Figure 4

Anechoic Chamber. Filled phantom in the shielded anechoic chamber.

cur. Therefore, we used broadband dipoles powered by a $\mathrm{RF}$ amplifier for the second part of the experiments.

\section{Tests of commercially available mobile phones}

The electromagnetic compatibility behavior of the ITRELIII was examined while exposing the ITREL-III to the fields of 10 different types of GSM $900 \mathrm{MHz}$ mobile phones and 10 different GSM $1800 \mathrm{MHz}$ mobile phones. Every mobile phone was tested in three different positions next to the phantom, using 2 different electrode configurations
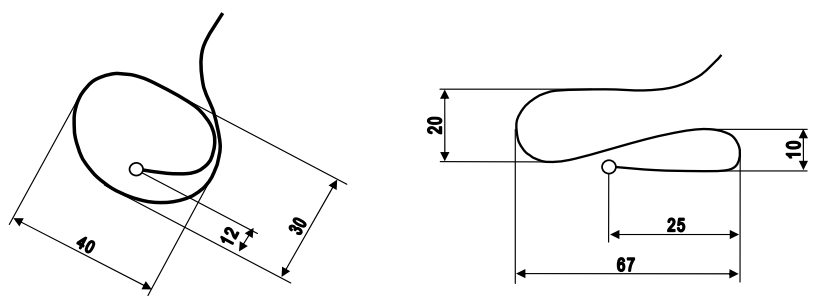

\section{Figure 5}

Lead Configurations. Lead configurations "loop" and "meander" around the entry point into the skull (white point); dimensions in millimeter.

and 8 different stimulation parameters, SeeFF Table 1. Altogether, 960 different test configurations were examined. The power control of the handsets was adjusted at 900 $\mathrm{MHz}$ and $1800 \mathrm{MHz}$ using the GSM tester "CMD 55" from Rhode \& Schwarz. The maximum radiated peak power was $2 \mathrm{~W}(+/-2 \mathrm{~dB})$ at $900 \mathrm{MHz}$ and $1 \mathrm{~W} \mathrm{(+/-2} \mathrm{dB)} \mathrm{at} 1800$ $\mathrm{MHz}$, respectively.

Different spatial configurations of the implant lead-shape and lead-size, can affect the interference due to different RF-behavior. Particularly, loops in the leads are able to pick up more RF currents. With respect to RF-behavior two significantly different lead configurations were chosen: the "loop" and the "meander." Figure 5 shows the two different lead configurations for interference testing.

All mobile phones were tested in three positions next to the phantom: 1 . in front of the chest - directly over the implant with the mobile phone touching the phantom; shown in Figure 6.

2. next to the ear - in a typical position while making a telephone call. This position is defined in [26] as the "cheek" or "touch" position; shown in Figure 7.

3. in a non-typical position in front of the skull directly over the loop or meander; shown in Figure 8.

To observe the function of the ITREL-III the output signal at the connection of the lead to the implant case was monitored via a shielded cable on an oscilloscope. Interference with the field of the mobile phone and the monitoring cable was prevented by routing the monitoring cable out of the phantom to the oscilloscope on the opposite side (back of the phantom) of the interference source.

Different mobile phones have different types of antennas and each antenna has its own current distribution. The current distribution on the antenna and the antenna loca- 


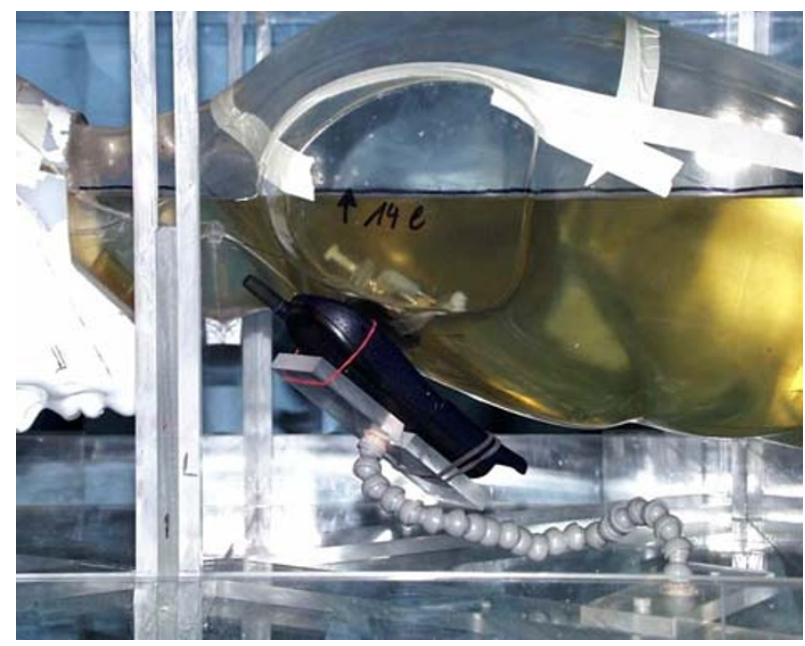

Figure 6

Mobile Phone Position I. Mobile phone directly over the implant.

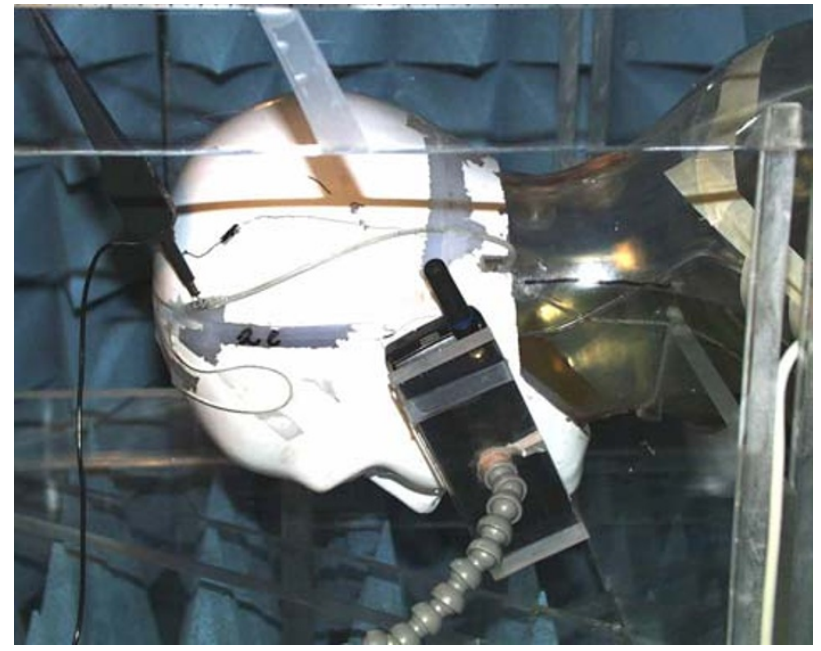

Figure 7

Mobile Phone Position 2. Mobile phone in „cheek" or „touch" position.

tion on the mobile phone case affects the field distribution in the patient and therefore the interference behavior. Another major difference between mobile phones is the emitted peak power due to the GSM specifications which allow a peak power tolerance of $+/-2 \mathrm{~dB}$. To get a representative coverage we tested 20 different GSM mobile phones indicated in Table 4 .

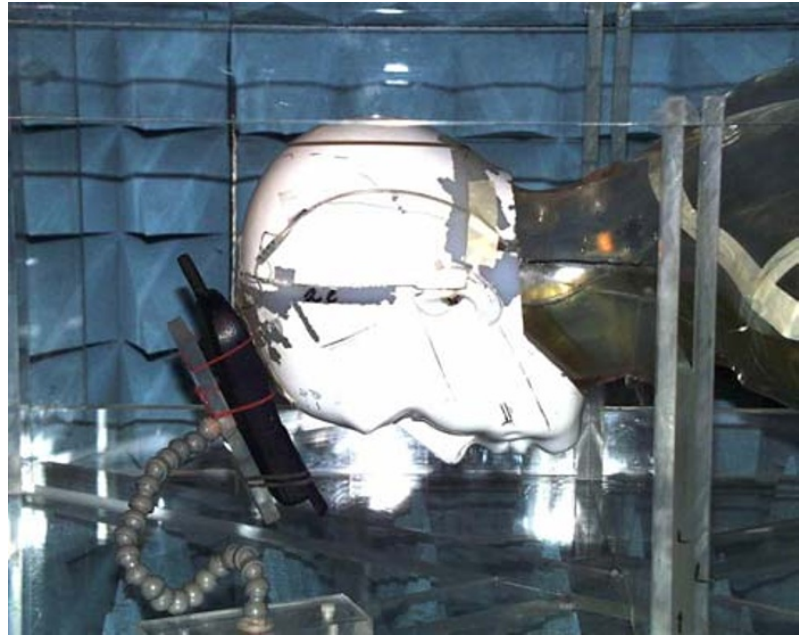

Figure 8

Mobile Phone Position 3. Mobile phone directly over the loop or meander.

Ad hoc testing of electronic implants with special types of mobile phones only gives reliable results for the tested phones. To know the safety margin for possible interference it is necessary to perform tests with more general interference sources. Therefore broadband dipoles were used to find out which power levels, depending on the frequency would cause interference.

\section{Susceptibility tests using broadband dipoles}

The purpose was to determine the interference level of the ITREL-III in the frequency range from $500 \mathrm{MHz}$ to 2400 $\mathrm{MHz}$. We used broadband dipoles shown in Figure 9. The dipole consists of two equilateral triangles with a length $\mathrm{L}$ of a quarter of the wavelength. We used two different broadband dipoles with dimensions for $900 \mathrm{MHz}$ and $1800 \mathrm{MHz}$. Dipoles were mounted on the surface of the phantom directly over the implant and driven by an RF amplifier. The RF signal was a continuous wave (CW). The dipole touched the surface of the phantom and had a distance of $13 \mathrm{~mm}$ to the surface of the ITREL-III $(3 \mathrm{~mm}$ phantom plastic shell and $10 \mathrm{~mm}$ phantom liquid, see Figure 9).

Such a scenario corresponds to the situation when a patient carries a mobile phone in his jacket. At each examined frequency, the transmitting power of the dipole was increased until the implant showed an influence. This power level is defined as the interference level. Special diligence was taken to measure the radiated power (forward minus reflected power). Generally, RF transmitter frequency tests were performed in frequency steps of $5 \mathrm{MHz}$. 
Table 2: Phantom Material Composition

\begin{tabular}{|c|c|c|c|c|}
\hline & \multicolumn{2}{|c|}{$900 \mathrm{MHz}$} & \multicolumn{2}{|c|}{$1800 \mathrm{MHz}$} \\
\hline & Brain & Muscle & Brain & Muscle \\
\hline & {$[\%]$} & [\%] & [\%] & {$[\%]$} \\
\hline \multicolumn{5}{|c|}{ Liquid phantom material } \\
\hline Water & 46.1 & 58.0 & 41.75 & 61.0 \\
\hline Salt & 1.0 & 1.2 & 0.0 & 0.3 \\
\hline Sugar & 46.6 & 39.7 & 57.75 & 37.6 \\
\hline Ethylene glycol & 5.2 & 0.0 & 0.0 & 0.0 \\
\hline Cellulose & 1.0 & 1.0 & 0.4 & 1.0 \\
\hline Bactericide & 0.1 & 0.1 & 0.1 & 0.1 \\
\hline \multicolumn{5}{|c|}{ Jelly phantom material } \\
\hline Water & - & 50.0 & - & 20.0 \\
\hline Salt & - & 1.5 & - & 2.0 \\
\hline Ethylene glycol & - & 28.4 & - & 58.0 \\
\hline Gelatin & - & 20.0 & - & 19.9 \\
\hline Bactericide & - & 0.1 & - & 0.1 \\
\hline
\end{tabular}

Composition of the liquid and the jelly phantom materials for brain and muscle simulating materials in mass \%

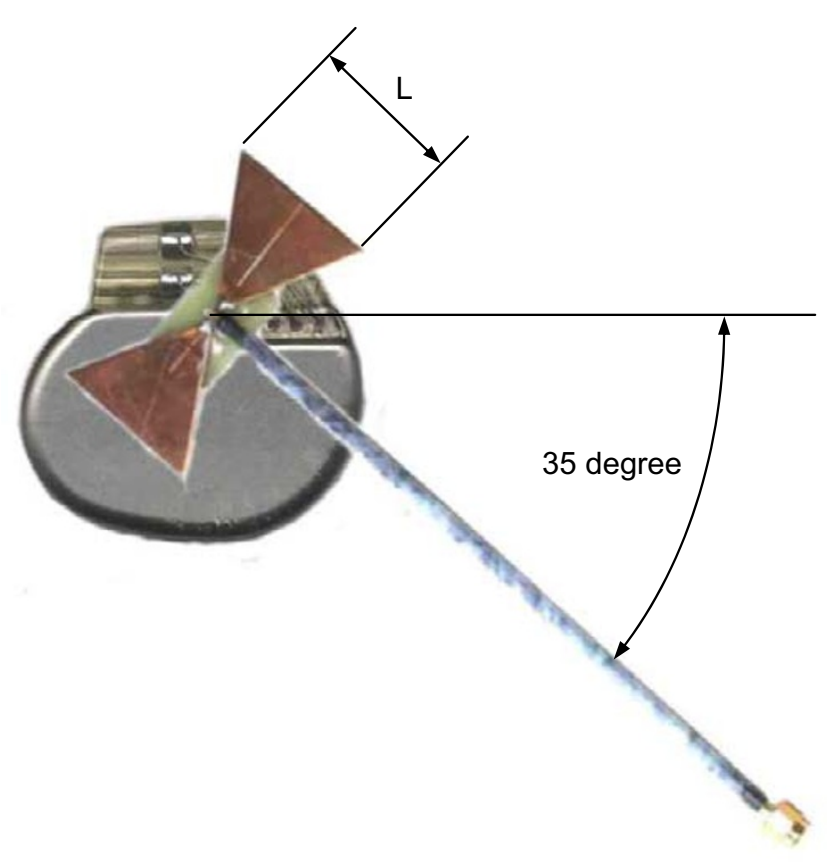

Figure 9

Broadband Dipole. $1800 \mathrm{MHz}$ broadband dipole over the ITREL-III; $L=0.25 \times$ wavelength. Distance between dipole and implant: $3 \mathrm{~mm}$ phantom plastic shell and $10 \mathrm{~mm}$ phantom liquid.
The frequency increment was reduced to $1 \mathrm{MHz}$ only in bands where low interference levels were observed.

To estimate the electric field (E field) inside the phantom at the position of the implant we modeled, at $900 \mathrm{MHz}$ and $1800 \mathrm{MHz}$, a simplified test setup using the Finite Difference Time Domain (FDTD) method with a grid size of $3 \mathrm{~mm}$. A half-wavelength dipole was placed directly on a $3 \mathrm{~mm}$ thick flat plastic layer. Behind the flat plastic layer we modeled the liquid phantom material with dielectric properties for "Muscle tissue" given in Table 3. The model with the resulting E field distribution at $1800 \mathrm{MHz}$ is shown in the results section in Figure 11.

\section{Results}

No influence on the ITREL-III was found during tests with GSM mobile phones despite a maximum transmission peak power of $1 \mathrm{~W}(1800 \mathrm{MHz})$ and $2 \mathrm{~W}(900 \mathrm{MHz})$. No inhibition or changes in the shape of the stimulation pulse occurred. Tests with broadband dipoles and different power levels showed that the output signal of the ITREL-III abruptly failed (inhibition) when the interference level was exceeded. The inhibition was complete, which means no output signal was detected and the ITREL-III stopped working. The ITREL-III returned to normal operation after reducing the transmit power below the interference level. The primary settings and programming parameters, like the amplitude and the pulse repetition rate of the output signal of the ITREL-III remained 
Table 3: Phantom Material Dielectric Properties

\begin{tabular}{|c|c|c|c|c|}
\hline \multirow[t]{3}{*}{ Material } & \multicolumn{2}{|c|}{$900 \mathrm{MHz}$} & \multicolumn{2}{|c|}{$1800 \mathrm{MHz}$} \\
\hline & $\varepsilon^{\prime}$ & $\varepsilon^{\prime \prime}$ & $\varepsilon^{\prime}$ & $\varepsilon^{\prime \prime}$ \\
\hline & {$[1]$} & {$[1]$} & {$[1]$} & {$[1]$} \\
\hline Muscle tissue & 55.9 & 19.4 & 54.4 & 13.9 \\
\hline Phantomliquid "Muscle" & 53.3 & 21.5 & 54.9 & 15.5 \\
\hline $\begin{array}{l}\text { Jelly phantom material } \\
\text { "Muscle" }\end{array}$ & 56.1 & 25.4 & 49.9 & 17.9 \\
\hline Brain tissue & 45.8 & 15.3 & 43.5 & 11.5 \\
\hline Phantom liquid "Brain" & 47.7 & 16.5 & 34.4 & 13.5 \\
\hline
\end{tabular}

Comparison of the dielectric properties, the permittivity $\left(\varepsilon^{\prime}\right)$ and the conductivity $\left(\varepsilon^{\prime \prime}\right)$, of brain, muscle tissue, and phantom materials

Table 4: Mobile Phones

\begin{tabular}{|c|c|c|c|}
\hline \multicolumn{2}{|c|}{$900 \mathrm{MHz}$} & \multicolumn{2}{|c|}{$1800 \mathrm{MHz}$} \\
\hline Manufacturer & Type & Manufacturer & Type \\
\hline Alcatel & One touch & Bosch & GSM 909 \\
\hline Ericsson & GF 768 & Ericsson & SH 888 \\
\hline Ericsson & GA 628 & Ericsson & A $1018 \mathrm{~S}$ \\
\hline Ericsson & GH 688 & Ericsson & $\mathrm{T} 18 \mathrm{~S}$ \\
\hline Nokia & 8105 & Mitsubishi & MT-040 \\
\hline Nokia & $8110 i$ & Motorola & Timeport \\
\hline Philips & Diga & Nokia & 6150 \\
\hline Philips & 747 & Nokia & 3210 \\
\hline Siemens & S4 & Sagem & M3I BO \\
\hline Siemens & S6 & Siemens & SI5E \\
\hline
\end{tabular}

Mobile phones used for interference tests at $900 \mathrm{MHz}$ and $1800 \mathrm{MHz}$

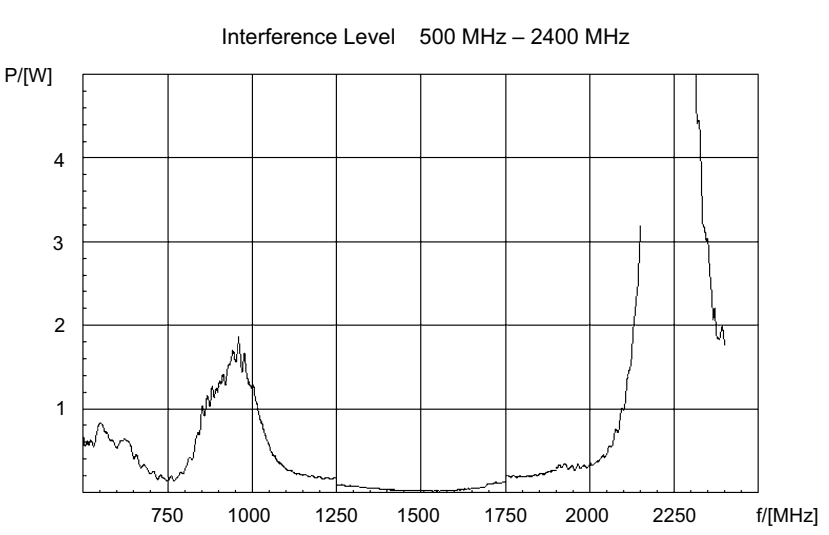

Figure 10

Interference Levels. Interference level of the ITREL-III in the frequency range from $500 \mathrm{MHz}$ to $2400 \mathrm{MHz}$. The interference level is defined as the minimum transmitted power level at which interference was detected. unchanged. This kind of implant behavior was found at all tested frequencies. Figure 10 shows the frequency dependence of the interference level.

The observed interference level at $900 \mathrm{MHz}$ was $1.24 \mathrm{~W}$ (CW) or $100 \mathrm{~V} / \mathrm{m}$ inside the liquid at the location of the implant and $0.14 \mathrm{~W}(\mathrm{CW})$ or $30 \mathrm{~V} / \mathrm{m}$ inside the liquid at the location of the implant at $1800 \mathrm{MHz}$. A variation of the stimulation parameters does not lead to any essential change of the threshold value. The extremely low interference level at $1500 \mathrm{MHz}$ should be noted. In this frequency range a few milli-watts $(3-10 \mathrm{~V} / \mathrm{m})$ were sufficient to inhibit the ITREL-III. Tests on other locations of the dipole relative to the phantom (near the ear, the loop or the meander) showed no influence up to a maximum available radiation power of $6 \mathrm{~W}$. The uncertainty of the transmitting power measurement was less than $\pm 30 \%$, and is basically composed of the uncertainty of the power meas- 


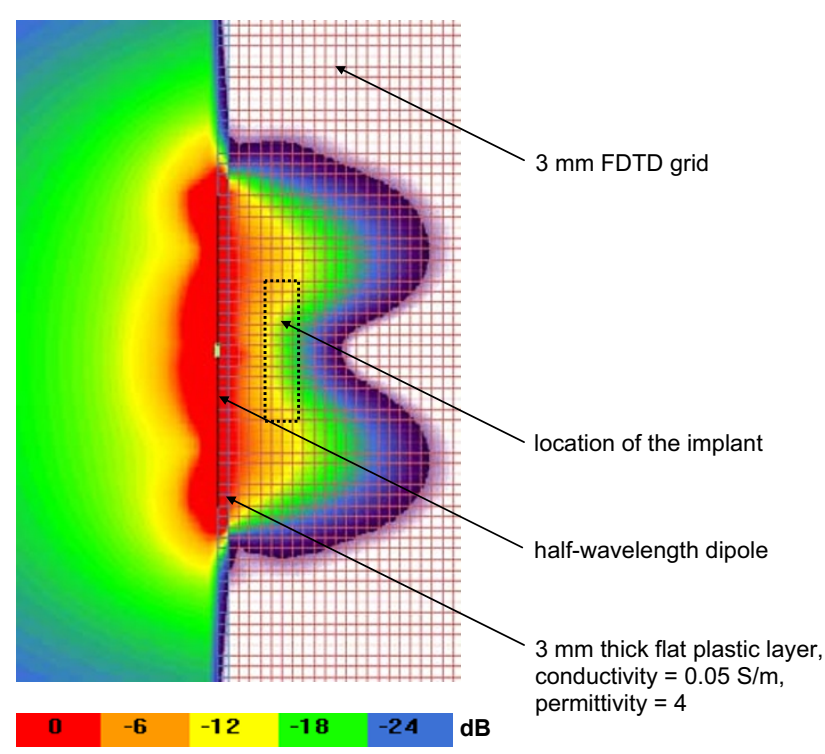

\section{Figure I I}

E Field Distribution. E field distribution inside a flat phantom at $1800 \mathrm{MHz}$ for a transmit power of $0.14 \mathrm{~W}$. The distribution is normalized to $120 \mathrm{~V} / \mathrm{m}$. The red area, $0 \mathrm{~dB}$, corresponds to an $E$ field of $120 \mathrm{~V} / \mathrm{m}$ or higher. One color step, 6 $\mathrm{dB}$, corresponds to an $\mathrm{E}$ field step of a factor 2 . The dashed area indicates the position of the implant $\mathrm{I} \mathrm{cm}$ below the surface of the phantom shell. Here the $E$ field is approximately $30 \mathrm{~V} / \mathrm{m}$ (yellow area, $12 \mathrm{~dB}$ below $120 \mathrm{~V} / \mathrm{m}$ ).

urement itself and the uncertainty of the direction coupler parameters.

Figure 11 shows the E field distribution for $1800 \mathrm{MHz}$ at a transmit power of $0.14 \mathrm{~W}$, which corresponds to the observed interference level at $1800 \mathrm{MHz}$. The magnitude of the $\mathrm{E}$ field at the location of the implant (dashed rectangle) is about $30 \mathrm{~V} / \mathrm{m}$. The calculation at $900 \mathrm{MHz}$ shows an E field of about $100 \mathrm{~V} / \mathrm{m}$ at the location of the implant for a transmit power of $1.24 \mathrm{~W}$.

\section{Conclusions}

The examinations have shown that the exposure of the ITREL-III to electromagnetic fields of GSM $900 \mathrm{MHz}$ and $1800 \mathrm{MHz}$ mobile phones does not result in inhibition or changes in the shape of the stimulation pulses. The investigations performed with mobile phones did not indicate a direct risk for ITREL-III patients while using the tested mobile phones in positions corresponding to the intended use. Tests with increased transmitting power have shown that an inhibition of the ITREL-III is caused at frequency dependent power levels. An "On/Off" switching of the reed switch of the implant could not be ob- served. Both interference levels found with CW signals using broadband dipoles $(1.24 \mathrm{~W}$ or $100 \mathrm{~V} / \mathrm{m}$ at $900 \mathrm{MHz}$ and $0.14 \mathrm{~W}$ or $30 \mathrm{~V} / \mathrm{m}$ at $1800 \mathrm{MHz}$ ) are below the maximum nominal peak power of GSM mobile phones. The GSM specifications allow a $+/-2 \mathrm{~dB}$ offset from the nominal output power of $2 \mathrm{~W}$ at $900 \mathrm{MHz}$ or $1 \mathrm{~W}$ at 1800 $\mathrm{MHz}$, respectively. Even the lower boundary of the GSM power specifications $(1.25 \mathrm{~W}$ at $900 \mathrm{MHz}$ and $0.63 \mathrm{~W}$ at $1800 \mathrm{MHz}$ ) are above the interference levels found with $\mathrm{CW}$ signals using broadband dipoles. The question of why we could not find interference with real GSM phones although the interference levels found with broadband dipoles are below the emissions of GSM specifications remains open. A possible explanation is that a mobile phone is covered with a plastic case with losses which absorb energy and therefore reduce the emitted fields. Our broadband dipoles were not covered with plastic. Furthermore the plastic case of the mobile phone prevents the antenna or other metallic parts from touching the phantom shell as with the broadband dipoles we used. Particularly low interference levels were observed in the frequency range around $1500 \mathrm{MHz}$. This frequency range is used by Japanese mobile phones. Further examinations including mobile phones operating in this frequency band are recommended. A major finding was the strong frequency dependent interference level. Due to lack of information about the implant, particularly details about the electronic circuit design, the reason for the strong frequency dependence of the interference level and the very low interference level around $1500 \mathrm{MHz}$ could not be determined. Other types of neurological stimulators could also have a frequency dependent interference level but with interference levels below the emissions of mobile phones at other frequencies. Unfortunately such neurological stimulators (e.g. ITREL-II, Soletra, Kinetra) were not available to perform similar tests. The assumption that the implant with a low battery level would be more susceptible to electromagnetic fields proved to be wrong. Both tested implants showed the same interference level. Regarding mobile phone safety of neurological pulse generators Medtronic only has information about the "Activa System" (Medtronic Web Site, http://www.medtronic.com/neuro/et/fields.html: Most of the electrical devices that people are around in a normal day will not harm the Activa System. This includes household appliances, computers, office machines, cellular phones, and personal radios. Special circuits inside the neurostimulator protect it from extreme electrical stress). Until information is available about the mobile phone compatibility of other neurological implants, especially older models, and there is a clarification of the ITREL-III interference below the emissions of GSM mobile phones, we recommend the following precautions based on investigations with cardiac pacemakers: 1 . To use the phone at the ear opposite the side of the implant and 2. To carry the cell phone on the opposite side of the implant 
when it is in use or in "stand-by" modus. Due to the fact we were not aware of any investigations on DBS and mobile phones using other technologies as Universal Mobile Telecommunications System (UMTS) we suggest that patients with DBS should take into account the safety recommendations given above.

\section{References}

I. Altamura $G$, Toscano S, Gentilucci $G$ and Ammirati $F$ Influence of digital and analogue cellular telephones on implanted pacemakers Eur Heart 1997, 18: 1632-1641

2. Barbaro V, Bartolini P, Donato A and Militello C Electromagnetic interference of analog cellular telephones with pacemakers: In vitro and in vivo studies Pace 1999, 22:626-634

3. Carillo RG, Williams DB, Traad EA and Schor JS Electromagnetic filters impede adverse interference of pacemakers by digital cellular telephones [Abstract] Journal of the American College of Cardiology 1996, 27(6): 15A

4. Chen WH, Lau CP, Leung S-K and Sai-Wah Ho D Interference of cellular phones with implanted permanent pacemakers Clin Cardiol 1996, 19:881-886

5. Ellenbogen KA and Wood MA Cellular telephones and pacemakers: Urgent call or wrong number? Journal of the American College of Cardiology 1996, 27(6): I 478-1479

6. Hayes D, Carrillo R, Findlay G and Embrey M State of the science: Pacemaker and defibrillator interference from wireless communication devices Pace 1996, 19:1419-1430

7. Hayes D, Wang P, Reynolds D and Estes M Interference with cardiac pacemakers by cellular telephones The New England Journal of Medicine 1997, 336(2I): 1473-1479

8. Irnich W, Batz L, Müller R and Tobisch R Electromagnetic interference of pacemakers by mobile phones Pace 1996, 19:14311446

9. Naegeli B, Osswald S, Deola M and Burkart F Intermittent pacemaker dysfunction caused by digital mobile phones Journal of the American College of Cardiology 1996, 27(6): | 47|-1477

10. Ruggera $P$, Witters $D$ and Bassen $H$ In vitro testing of pacemakers for digital cellular phone electromagnetic interference $B i$ omedical Instrumentation \& Technology 1997, 3 I (4):358-37|

II. Sparks P, Mond H, Joyner K and Wood M The safety of digital mobile cellular telephones with minute ventilation rate adaptive pacemakers Pace 1996, 19:|45|-455

12. Tan $\mathrm{K}$ and Hinberg I Laboratory investigation of wireless digital communication system interference with implantable cardiac pacemakers WTR Symposium Washington DC 1996,

13. Trigano A, Azoulay A, Rochdi M and Campillo A Electromagnetic interference of external pacemakers by walkie-talkies and digital cellular phones: experimental study Pace 1999, 22:588593

14. Wilke A, Grimm W, Funk R and Maisch B Influence of D-Net (European GSM-Standard) cellular phones on pacemaker function in $\mathbf{5 0}$ patients with permanent pacemakers Pace 1996 , 19:| $456-\mid 458$

15. Nowak B, Rosocha $S$, Zellerhoff $C$ and Liebrich $A$ Is there a risk for interaction between mobile phones and single lead VDD pacemakers? Pace 1996, 19:| 1447-|450

16. Ravindran A, Schlegel R, Grant $H$ and Raman $S$ In vitro study of the interaction between wireless phones and cardiac pacemakers WTR Symposium Washington DC 1996,

17. Raychowdhury G, Biswas A, Mitra K and Dasbiswas A Interference of pacemaker by mobile phones [Abstract] Pace 1997, 20(II):2337

18. Ruggera $P$, Ravindran $A$, Tan $K$ and Hayes $L$ Evaluation of the potential for hand held wireless telephones to interfere with implanted cardiac pacemakers Wireless Technology Research Scientific Symposium Washington DC 1996,

19. Barbaro V, Bartolini P, Bellocci F and Donato A Electromagnetic interference of digital and analog cellular telephones with implantable car-dioverter defibrillators: In vitro and in vivo studies Pace 1999, 22:626-634

20. Bassen $H$, Moore $H$ and Ruggera $P$ Cellular phone interference testing of implantable cardiac defibrillator, in-vitro Circulation 1995, 92:1-738
21. Kainz $W$ and Neubauer $G$ Electromagnetic compatibility (EMC) of electronic implants Austrian Research Centers Seibersdorf Report, OEFZS-E-0004 1999,

22. Kainz W, Neubauer G, Alesch F, Schmid G and Jahn O Electromagnetic Compatibility of Electronic Implants - Review of the Literature Wiener Klinische Wochenschrift 200I, I I 3:23-24

23. Alesch F, Pinter MM, Helscher RJ, Fertl L, Benabid AL and Koos WT Stimulation of the ventral intermediate thalamic nucleus in tremor dominated Parkinson's disease and essential tremor Acta Neurochir 1995, I36( I-2):75-8I

24. Limousin P, Pollak P, Benazzouz A, Hoffmann D, Le Bas JF, Broussolle $E$, Perret JE and Benabid AL Effect of parkinsonian signs and symptoms of bilateral subthalamic nucleus stimulation Lancet 1995, 345(8942):91-95

25. Gabriel S, Lau R and Gabriel C The dielectric properties of biological tissues: II. Measurements in the frequency range 10 Hz to 20 GHz Phys Med Biol 1996, 41:225I-2269

26. Institute of Electrical and Electronics Engineers (IEEE) SCC34 Draft Standard Recommended Practice for Determining the Peak Spatial-Average Specific Absorption Rate (SAR) in the Human Body Due to Wireless Communications Devices: Experimental Techniques IEEE Std I528-2002

Publish with Bio Med Central and every scientist can read your work free of charge

"BioMed Central will be the most significant development for disseminating the results of biomedical research in our lifetime. "

Sir Paul Nurse, Cancer Research UK

Your research papers will be:

- available free of charge to the entire biomedical community

- peer reviewed and published immediately upon acceptance

- cited in PubMed and archived on PubMed Central

- yours - you keep the copyright 